\title{
La filosofía clásica alemana es obra de teólogos encubiertos: el protestantismo en la génesis del idealismo alemán
}

\author{
Virginia López-Domínguez
}

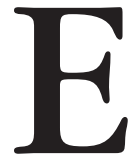

n el parágrafo diez del Anticristo, haciendo uso de su prosa más corrosiva, Nietzsche deja en claro la relación que liga a la filosofía clásica alemana con el protestantismo:

Entre alemanes se me comprende en seguida cuando yo digo que la filosofía está corrompida por sangre de teólogos. El párroco protestante es el abuelo de la filosofía alemana; el protestantismo mismo, su peccatum originale. Definición del protestantismo: la hemiplejía del cristianismo... y de la razón... Basta pronunciar la palabra "Seminario de Tübingen" para comprender qué es en el fondo la filosofía alemana -una teología artera. ${ }^{1}$

Esta declaración, escrita por Nietzsche en Italia poco antes de que fuera ingresado en un hospital psiquiátrico para el resto de su vida, cierra con lucidez magistral su constante diatriba contra la religión y la moral dicotómica, que, en este texto, se ejemplifica a través de la religiosidad suaba, de la filosofía de Kant y de aquellos que creyeron ver en su modo de pensar el inicio de una auténtica revolución cultural, es decir, de los idealistas y, en especial, de Hegel. ${ }^{2}$ En los

${ }^{1}$ Friedrich Nietzsche, El Anticristo. Maldición sobre el cristianismo. Trad. y notas de Andrés Sánchez Pascual. Madrid, Alianza, 1998, \10, p. 34. Las cursivas son mías.

2 "Del sistema de Kant y de su último perfeccionamiento espero una revolución en Alemania -una revolución que partirá de principios ya existentes, que sólo necesitan una elaboración general para ser aplicados a todo el saber que ha existido hasta ahora... Va a dar vértigo esta suprema cumbre de toda la filosofía que eleva de tal forma al hombre [...]. Que la humanidad se represente como tan digna de respeto a sí misma es una prueba de que el nimbo que rodeaba las cabezas de los opresores y de los dioses de la Tierra desaparece" (Carta de Hegel a Schelling del 16 de abril de 1795. G. W. F. Hegel, Escritos de juventud. Trad. de Zoltan Szanky y José María Ripalda. México, FCE, 1978, p. 61). 
parágrafos inmediatamente anteriores se define al párroco protestante y a los que tienen "sangre de teólogo" como representantes del nihilismo, negadores de la vida, calumniadores y envenenadores, que adoptan de antemano, frente a todas las cosas, una actitud torcida y deshonesta, porque, escudándose en el espíritu, tergiversan los valores vitales y, con soberbia, presentan lo ideal como lo más elevado, a pesar de que "el espíritu puro es la mentira pura". ${ }^{3}$

Con igual acritud y tono satírico, se refiere Schopenhauer a los idealistas desde su primera obra, porque simulan haber cerrado a Dios la puerta de entrada en sus enormes edificios conceptuales en nombre de la razón, pero, taimados y astutos, le abrieron la puerta de atrás en nombre de lo Absoluto, "como si la filosofía fuera teología y no buscase la explicación del mundo sino la de Dios". "Apreciaciones similares se esparcen también por La ideología alemana de Marx y Engels, con las cuales se intenta mostrar que gran parte del idealismo puede considerarse como una transposición en términos filosóficos de cuestiones religiosas. Y esto ocurrió porque -según explica J. M. Ripalda en la Introducción a los Escritos de juventud de Hegel- ${ }^{5}$ en esa época la teología se había convertido en campo de discusión donde se dirimían todos los problemas, debido a que la educación había sido monopolizada por distintas sectas protestantes. Por una parte, la teología apuntalaba el antiguo régimen, pero, por otra, servía también para anunciar una verdadera revolución. ${ }^{6}$

Efectivamente, si atendemos a la formación de los filósofos de esta época, casi todos habían estudiado teología, ya que era una vía cómoda para acceder a estudios universitarios humanísticos. En última instancia, las clases altas, las clases cultas de Alemania eran profundamente religiosas. Y esto tiene que ver con la estrategia utilizada por Lutero para lograr la supervivencia y expansión de sus doctrinas. Al admitir que, en el reino interior, el hombre debía obediencia a Dios, pero, en el reino externo, el ciudadano tenía que someterse a los

${ }^{3}$ F. Nietzsche, op. cit., $₫ 9$, p. 33.

${ }^{4}$ Arthur Schopenhauer, La cuádruple raíz del principio de razón suficiente. Trad. de M. Palacios. Madrid, Gredos, 1981, p. 76. Véase también el cap. 20, pp. 72-76.

${ }^{5}$ J. M. Ripalda, "Introducción", en G. W. F. Hegel, op. cit., pp. 25 y ss.

${ }^{6}$ Por una parte, dice Hegel en la carta a Schelling del 16 de abril de 1795: "Religión y política se han puesto de común acuerdo: aquélla ha enseñado lo que quería el despotismo" (G. W. F. Hegel, op. cit., p. 61). Por otra parte, los seminaristas de Tübingen se despedían en nombre del reino de Dios en la Tierra, que simboliza la concreción en el mundo del reino de los fines kantianos o el reino del espíritu según la imagen del Tercer Evangelio de Joaquín de Fiore (siglo XII), esto es, de una comunidad de monjes que traería el acuerdo del reino del Padre (judaísmo) y el del Hijo (cristianismo). Las ideas joaquinistas fueron difundidas por Lessing en su Educación del género humano (1780). Así, en una carta de enero de 1795, Hegel se despide de Schelling incitándolo a una actitud revolucionaria con estas palabras: "Que venga el Reino de Dios y no estemos mano sobre mano” (G. W. F. Hegel, op. cit., p. 56). 
príncipes, realizó la alianza entre religión y poder político, evitando posibles revueltas y unificando la posición alemana en la lucha contra la Iglesia católica, porque se aunaba el poder de los príncipes y la aristocracia en contra de los emperadores católicos.

Pero, además, tal y como se hace notar en el parágrafo diez del Anticristo, la religiosidad dominante, tenía su baluarte en Suabia, en el ámbito cultural era el pietismo, una secta protestante muy estricta desde el punto de vista del comportamiento moral.

De hecho, si hacemos una rápida revisión de los principales personajes de la literatura y la filosofía de la época, incluso sin circunscribirnos a Suabia, se observa que la mayoría profesaba el pietismo: Lessing, por ejemplo, y también Kant, por vía materna. Eso, sin contar con que, además, Kant estudió en el Colegio Fridericianum, dirigido por el predicador áulico pietista Franz Albert Schultz, y que su maestro en la Universidad de Königsberg, Martin Knutzen, también pertenecía a esta secta. Y no hay que creer por esto que dicha religiosidad era patrimonio exclusivo de los ilustrados, porque, si apuntamos al otro lado de la Aufklärung, al Sturm und Drang, nos encontramos con que Hamann y Herder eran pietistas, además de que este último ejercía como pastor.

Entre los idealistas, Fichte no fue pietista por la educación que recibió en su familia sino porque realizó sus estudios primarios y secundarios becado en la escuela Pforta. Esta escuela era considerada como un centro de formación de élites en Alemania, ya que su alumnado procedía de altos estratos sociales y, en numerosos casos, terminó ocupando puestos relevantes en la administración del Estado, así como en el estamento religioso. Allí estudiaron importantes personajes de la cultura de aquel tiempo, como Klopstock, Lessing, Novalis y, más tarde, Nietzsche, en una atmósfera moral e intelectual decididamente pietista, un ambiente en extremo riguroso que, sin duda, contribuyó al rechazo frontal que este último sintió frente a la religión. ${ }^{7}$

En el caso de Schelling, el padre era diácono de la Iglesia protestante de su pueblo natal, Leonberg, conocido teólogo, aunque orientalista, lo cual le permitió abrirse a otras perspectivas religiosas más acordes con su inicial panteísmo. Sin embargo, por parte de su familia materna estaba conectado con varios intelectuales de la tradición teológica pietista de Würtemberg, a la cual pertenecieron Christoph Friedrich Oetinger -el mago del Norte-, Christoph Matthäus Pfaff, Johann Albert Bengel o Philipp Matthäus Hahn, a quien Schelling dedicó una elegía a los 15 años, lo cual pone en evidencia su grado de implicación en el grupo. ${ }^{8}$

${ }^{7}$ Cf. Virginia López-Domínguez, "La escuela Pforta", en Fichte: acción y libertad. Madrid, Ediciones Pedagógicas, 1995, pp. 29-33.

${ }^{8} C f$. "Introducción", en F. W. J. Schelling, Sistema del idealismo trascendental. 
Vinculado a esta misma tradición -la suaba-, estaba Hölderlin. Su preceptor fue Nathaniel Köstlin, tío de Schelling. ${ }^{9}$ Y por supuesto también lo estaba Hegel, ya que tanto el Seminario de Tübingen como su Universidad eran centros de ortodoxia pietista. Tampoco está demás recordar que Kierkegaard perteneció a esta secta protestante y que gran parte de sus ideas filosóficas pueden ser interpretadas como una reacción ante las creencias y prácticas religiosas del grupo.

Así pues, parece ser que Nietzsche tenía entonces razón: la filosofía clásica alemana es obra de teólogos encubiertos, pero hay que reconocer que en esa época la teología no sólo influyó en el pensamiento filosófico para prolongarse en él buscando su justificación, sino para encontrar un rechazo a la ortodoxia y aspirar a la superación de la religión en la propia filosofía.

\section{El pietismo y su influencia en la gestación del idealismo}

El pietismo surgió en Alemania desde el seno mismo de la religión protestante, como una reacción crítica ante el desarrollo de la Reforma. Sin embargo, forma parte de un movimiento más amplio de radicalismo religioso que se extendió por Europa en el siglo XVII, por ejemplo, a través del jansenismo en Francia o el puritanismo en Inglaterra. Con Lutero, la Reforma se había abierto paso exigiendo tolerancia ante las otras religiones y una mayor libertad de espíritu frente a las autoridades eclesiásticas, pero, a medida que avanzaba y ganaba adeptos, fue contradiciendo también su espíritu primitivo. Por una parte, la violencia entre cristianos y católicos fue en aumento hasta plasmarse, por ejemplo, en la Guerra de los 30 años, a la vez que las relaciones entre Estado y religión se iban deteriorando. Por otra parte, en su intento de consolidarse, el protestantismo había ahogado las enseñanzas luteranas con un formalismo escolástico e inerte, regido por prácticas estereotipadas y especulaciones de teólogos y filósofos. Tanto a nivel práctico como teórico, el movimiento protestante estaba desgarrado por luchas y controversias.

En el siglo XVII, Philipp Jakob Spener, intentó poner fin a esta situación agónica e inició un movimiento de recuperación y renovación del espíritu originario de la Reforma, que aspiraba a una cristiandad unida por lazos amorosos, iluminada por Dios, en su aspiración hacia la verdad. Spener era un intelectual, liberado de sus obligaciones pastorales, que se había graduado en teología con una tesis contra Hobbes, lo cual da la pauta de su aversión al

Trad., introd. y notas de V. López-Domínguez y J. Rivera de Rosales. Barcelona, Ánthropos, 1988, p. 12.

9 Véase Martín Rodríguez Baigorria, "Hölderlin y el contexto cultural pietista", en Revista de Filología Alemana, vol. 19, 2011, pp. 103-114. 
Estado y al pragmatismo político. El movimiento que lo siguió, el pietismo, se hizo eco de la necesidad de encontrar en la intimidad espiritual una guarida ante el materialismo circundante, desde la cual proteger la libertad de cada uno y acometer un verdadero renacimiento del alma, una reforma interior apoyada sólo en la voluntad individual, sin ayuda de autoridad ninguna, tan sólo iluminada por la Gracia. ${ }^{10}$ Se trataba de efectuar un cambio a nivel espiritual, una reforma del pensar, previa y necesaria para cualquier transformación externa, incluyendo la revolución política, como más tarde pensarán Kant, por ejemplo, en su artículo sobre "Qué es la Ilustración" o el Fichte de $\mathbf{L a}$ reivindicación de la libertad de pensamiento a los príncipes de Europa que hasta ahora la oprimieron.

La idea de que la hazaña filosófica que representan los grandes sistemas del idealismo alemán habría sido imposible de realizar si no hubiese existido la Reforma protestante y que, de alguna manera, la eclosión intelectual constituye una especie de desquite ante las dificultades de Alemania para emprender su liberación del régimen feudal a través de una revolución política semejante a la de Francia, es un tópico repetido muchas veces, que nace a mediados del siglo XIX, cuando el idealismo había llegado a su término y culminación. Aparece, por ejemplo, en Sobre la historia de la religión y la filosofía en Alemania de Heine:

La filosofía alemana posee un gran valor, es un problema que concierne a toda la especie humana y que únicamente nuestros descendientes más lejanos estarán en condiciones de juzgar si merecemos el elogio o la censura por haber concebido nuestra filosofía antes de haber hecho nuestra revolución. Me parece que un pueblo tan metódico como el nuestro debía comenzar por la Reforma, para ocuparse luego de la filosofía, y es sólo después de haberla terminado por completo que nos resultó posible pasar a la revolución política. El pensamiento precede a la acción así como el relámpago precede al trueno. Pero el trueno es ciertamente alemán; no es rápido, en efecto, y se aproxima con marcada lentitud; sin embargo termina por estallar. Entonces, al escuchar un estampido tal como jamás ha resonado en la historia universal, sabedlo bien: el trueno alemán, a la postre, alcanzará su fin. ${ }^{11}$

De este modo, atento a la preparación de la reforma interior, el pietismo cuajó sobre todo en el ámbito educativo y así es como se dio la mano con el

${ }^{10}$ Sobre el pietismo y su fundador, véase J. Wallmann, Philipp Jakob Spener und die Anfänge des Pietismus. Tübingen, Mohr, 1986 y J. Wallmann, Der Pietismus. Göttingen, Vandenhoeck \& Ruprecht, 2005.

${ }^{11}$ Heinrich Heine, Sobre la historia de la religión y la filosofía en Alemania. Trad. de M. Sacristán. Madrid, Tecnos, 2015, p. 276 [Heines Werke, XI]. 
movimiento ilustrado. Igual que él, pretendía la formación de individuos cada vez más cultos, con más conocimientos, pero lo hacía con el fin de expandir a través de ellos la fe protestante, aunque sin prejuicios, con inteligencia y tolerancia. Sin embargo, no privilegió la razón teórica como instrumento para alcanzar esos conocimientos sino que retomó el principio luterano de que lo divino se encuentra en el corazón de cada uno y, así, defendió una vuelta a la interioridad por la fe, en cuanto único lazo vivo que asegura una relación personal con Dios. De ahí que estos filósofos que hemos calificado de pietistas se centrarán en la subjetividad como punto de partida de su filosofía e intentarán ampliar la razón hacia otros campos más allá de la teoría: hacia la razón práctica (Kant y Fichte), la estética (Schelling y los románticos) o la especulativa (Hegel). De ahí también que especialmente los Stürmer como Herder y Hamann reivindicaran las emociones, lo intuitivo y lo individual frente a lo general, o que, incluso, a partir de ellos, surgiera en la época (la de Aufklärung) toda una corriente denominada "Filosofía de la fe" (Glaubensphilosophie), representada por Hamann y Jacobi. En el caso de este último autor, su modo de hacer filosofía asumía tintes radicales, ya que se apoyaba en un rechazo completo de la inteligencia teórica debido a su capacidad para negar, para aniquilar la vida y el mundo, por lo que llamó a su pensamiento No-filosofía (Unphilosophie). ${ }^{12}$ Más tarde, Hegel asumió la idea de que la operación característica del entendimiento es la negación, si bien dentro de un contexto más amplio, el de la razón (caracterizada por su funcionamiento dialéctico), que intenta neutralizar y superar lo negativo mediante una síntesis con lo afirmativo. ${ }^{13}$

Pero, además, a resultas de este retorno a la conciencia individual como lugar preeminente de manifestación de la divinidad, el pietismo pregonó que el autoanálisis era un camino privilegiado de purificación conducente a la santidad. Y, de esta manera, abrió una serie de expectativas escatológicas, un cierto milenarismo, que predicó la inminente llegada del reino de Dios a la Tierra. Esta idea, operante sobre todo en el ámbito de la tradición de Würtemberg, alimentó las ansias republicanas y el apoyo "sentimental" a la Revolución francesa por parte de los jóvenes seminaristas de Tübingen: Hölderlin, Hegel y Schelling. ${ }^{14}$

${ }^{12}$ Cf. H. Jacobi, David Hume über den Glaubens, oder Idealismus und Realismus. Ein Gespräch (1787). Sobre el pensamiento de este autor, véase J. L. Villacañas, Nihilismo, especulación y cristianismo en F. H. Jacobi. Ensayo sobre los orígenes del irracionalismo contemporáneo. Barcelona, Ánthropos, 1989.

${ }^{13}$ Véase, por ejemplo, G. W. F. Hegel, "Prólogo", en La fenomenología del espíritu. Ed. bilingüe de A. Gómez Ramos. Madrid, Abada/UAm, 2010.

${ }^{14}$ Esto último ocurrió sobre todo en el pietismo suabo, por ejemplo, con Bengel y Hahn. El tío de Schelling, Nathaniel Köstlin, tutor escolar del filósofo y maestro particular de Hölderlin, perteneció a este grupo de milenaristas. El otro referente de la 
Está claro, entonces, que con el correr de los años el movimiento pietista consiguió ejercer una fuerte influencia en la educación teológica de la juventud alemana y que, sobre finales del siglo XVIII, principios del XIX, muchos personajes intelectualmente destacados habían recibido influjo directo o mediato de este tipo de religiosidad. Sin embargo, con el incremento y el desarrollo del pietismo, el ideal primitivo de pureza fue degenerando en un rigorismo moral extremo por parte de sus adeptos. Sus huellas se conservan en la primera ética kantiana, por ejemplo, en La fundamentación de la metafísica de las costumbres, donde los actos efectuados por inclinación inmediata, o sea, los movidos por el amor a alguien concreto, se desestiman como obras morales, porque la primera causa de su realización no se encuentra en el deber, no tienen su origen en una idea de la razón, sino que están impelidos por un sentimiento, pudiendo coincidir o no con el imperativo categórico, que ordena la universalización de la máxima de la acción.

Al final, dada la enorme dificultad de comprobar la intención, el aspecto interior y subjetivo de la acción, el pietismo terminó por entrar en contradicción consigo y se exteriorizó en un patrón mecánico, en un conjunto de técnicas expiatorias, como rezos, prácticas devotas, sermones y, sobre todo, en una torturante y meticulosa fiscalización interior. Según Hegel, esto es lo que caracteriza a la conciencia infeliz. La conciencia desdichada es para él una figura esencialmente religiosa, aunque su dinámica pueda aplicarse a cualquier otra circunstancia, y se relaciona con los monoteísmos, que presentan una dualidad y un enfrentamiento directo entre el hombre y Dios. Como es obvio, se da en el judaísmo, pero en la Fenomenología del espíritu Hegel desarrolla de modo preferente su raigambre cristiana, refiriéndose tanto a sus orígenes como a su desarrollo, sobre todo, a la versión luterana, para la cual evidentemente toma como modelo la interpretación pietista. La conciencia desdichada interioriza su separación de lo divino que se le opone y concluye por escindirse de sí misma. Cuando se materializa y se plasma en el mundo, por ejemplo, en su obra o en su acción, sólo siente que lo hace parcialmente, como si concretase un único aspecto de la realidad que fustiga a la otra parte, a la cual considera enemiga, opuesta o diabólica. Por eso, se abstiene permanentemente de esa

creencia en la inminente llegada del reino celeste a la Tierra es Joaquín de Fiore, quien predicó el advenimiento de un reino espiritual y de justicia, cuya búsqueda inspiró las revueltas de campesinos de Thomas Müntzer en la Alemania del siglo XVI. Los jóvenes seminaristas de Tübingen (Hegel, Hölderlin y Hegel) se adhirieron a estas convicciones, que implicaban una comprensión de la historia a partir del misterio de la Trinidad y que ellos relacionaron, por una parte, con la polémica entre antiguos y modernos, y con la llegada de un tercer periodo de conciliación de los anteriores en una etapa similar al reino kantiano de los fines, planteado no como idea regulativa, sino como un acontecimiento futuro, histórico y real. 
otra parte y así genera una moral ascética, de repudio a lo sensible, que se traspone filosóficamente a través de conceptos negativos de la subjetividad o de la espiritualidad, como son los de cosa en sí o de No-yo. Los idealismos de Kant y Fichte -siempre según Hegel-son plasmaciones filosóficas de esta clase de conciencia dividida. ${ }^{15}$

De hecho, la escuela Pforta participaba de este espíritu generalizado de mecanización y reglamentación de la piedad haciendo uso de una disciplina estricta y un tanto fanática, que fue asumida por los alumnos bajo la forma de un cierto sadismo contra los más débiles, como le ocurrió a Fichte. Trazas de este rigorismo quedaron también en él, como lo prueba su Diario, ${ }^{16}$ ya que, durante su estancia en la escuela, realizaba constantes exámenes de conciencia con estricta severidad (igual que Hölderlin). Sin embargo, está claro también que Fichte consiguió superar dicho rigor -no, en cuanto a las exigencias de su moral, pero sí en cuanto al repudio de las emociones-, porque su "idealismo ético" admite que los sentimientos contribuyen de manera positiva e inevitable a la constitución del pensamiento racional. ${ }^{17}$ En este punto, Fichte no hacía sino seguir la idea de la primacía luterana del criterio del corazón y del individuo por encima de la inteligencia y las instituciones.

La disciplina de Pforta, en cambio, fue rechazada por él -igual que sucedió con Nietzsche- e incluso terminó escapándose del colegio. Y tan pronto inició su camino filosófico, su primera preocupación fue la de examinar los dogmas religiosos a la luz de la razón, como ejemplifica su temprano Ensayo de una crítica de toda la revelación. Fichte siempre creyó que el protestantismo había conseguido depurar el cristianismo hasta su más alto grado y que, por tanto, era la forma de religiosidad más elevada. Sin embargo, rechazó de plano la creencia en un dios personal, que pudiera interpretarse como un dispensador de bienes y castigos, y por eso se le acusó de ateísmo. ${ }^{18}$ Así, el dios fichteano

${ }^{15}$ En la Fenomenología del espíritu, Hegel dedica un capítulo de la "Autoconciencia" a la conciencia desdichada y sus momentos. Al comienzo del mismo, hace velada referencia a las filosofías de Kant y Fichte. Sobre este tema y su relación con el pietismo, puede verse M. Schlette, "Das unglückliche Bewusstsein im Pietismus: Herrkunft und Säkularizierung im Anschluss an Hegel”, en Hegel-Jahrbuch. Berlín, 2005, pp. 236-242.

${ }^{16}$ Véase Fichtes Briefwechsel. Ed. de V. Hans Schulz. Hildesheim, Georg Olms, 1967, I, 12, pp. 20 y ss.; 64, pp. 153 y ss., y 95, p. 233.

${ }^{17}$ En la parte práctica de la Fundamentación de toda la doctrina de la ciencia, Fichte deduce los sentimientos, cuya función es tomar conciencia de lo que sucede al yo. Véase V. López-Domínguez, "El impulso y los sentimientos como motores de la vida práctica", en Fichte: acción y libertad, pp. 122-125.

${ }^{18}$ Esta acusación se produjo con motivo de la publicación en 1798 del artículo de Fichte titulado "Sobre el fundamento de nuestra fe en un orden divino del mundo". Sobre el tema, puede verse la obra colectiva: J. Rivera de Rosales y O. Cubo Ugarte, eds., La polémica sobre el ateísmo. Fichte y su época. Madrid, Dickinson, 2009. 
se constituye relacionalmente, como un "orden", un ordo ordinans, es decir, un conjunto de conexiones espirituales absolutas, algo así como el reino de los fines de Kant. Por supuesto, ésta es también, poco más o menos, la idea de cristiandad de Spener, inspirada en gran medida en el símbolo de la Ciudad de Dios de san Agustín, una comunidad puramente espiritual cuyo miembros se interrelacionan a través del amor.

A hora bien, lo que impresionó notablemente a todos los que acudieron en esa época a la escuela Pforta es la difusión que en ella se hacía del pensamiento de Lessing, a pesar de que muchos de sus escritos estaban prohibidos. Fichte, por ejemplo, leyó allí el AntiGoeze, gracias a las entregas que un profesor de Pforta fue haciendo secretamente de la polémica. Sabemos también que Nathan, el sabio era la obra preferida de Hegel desde su adolescencia. ${ }^{19}$ En cualquier caso, la enseñanza de Lessing coincidía con el protestantismo e incluso con los ideales educativos de la institución, a pesar de que abiertamente no podían admitirlo. Partiendo de la exigencia luterana de aceptar la libre interpretación de los textos sagrados, Lessing profesaba la tolerancia religiosa. Por ejemplo, en Nathan aparece la famosa parábola del anillo con la que se intenta mostrar que las tres religiones monoteístas son como los dedos de una mano, es decir, expresiones o desarrollos de un tronco común, de una misma verdad, una parábola que se desarrollará conceptualmente en La educación del género humano.

Las obras de Lessing reforzaban la idea de que la verdad -igual que Dios- reside en el corazón, pero colocaban esta vía en pie de igualdad con la inteligencia, generando dos ámbitos bien diferenciados: el de la fe y el de la razón, independientes entre sí y cada uno válido según sus propias leyes, de tal modo que es tarea absurda e impropia la de juzgar con las normas de una de sus esferas los principios de la otra intentando una descalificación radical de cualquiera de ellas. Pero además, Lessing descubrió a estos jóvenes el derecho del filósofo a pensar sobre la fe sin condicionamiento alguno. Su ejercicio vino a demostrarles que la revelación contiene muchos puntos insostenibles, que la moral es independiente de los dogmas y que no se puede privilegiar la revelación cristiana, puesto que sólo se trata de un hecho histórico entre otros. En suma, a través de Lessing atisbaron por primera vez ese repelente foso entre las verdades racionales y las verdades históricas, contingentes, que nunca pueden ser prueba de las primeras. ${ }^{20}$ Pero también conocieron su intento por superarlo, llevado a cabo en la Educación del género humano, donde

${ }^{19}$ T. Pinkard, Hegel. Una biografía, pp. 38 y ss.

${ }^{20}$ G. E. Lessing, "Ueber den Beweis des Geistes und der Kraft", en Sämtliche Schriften. Ed. De Lachmann-Muncker. Leipzig/Stuttgart, G. J. Göschen, 1904, t. XIII, pp. 5 y ss. 
la razón es concebida dinámicamente a través de un proceso de paulatinas revelaciones que se concretan en la historia y constituyen en su conjunto un plan divino de educación de la humanidad. Esta idea del dinamismo de la razón, magistralmente expresada por Lessing en su parábola de la verdad, ha sido, sin duda, una de las sugerencias más fructíferas que este pensador aportó al idealismo:

No es la posesión de la verdad, a la que ningún hombre llega ni cree llegar, es el esfuerzo sincero por conseguirla lo que le otorga valor, pues no es por la posesión de la verdad sino por su búsqueda, que sus fuerzas se desarrollan; en esta busca consiste su perfección y gracias a ella se engrandece. La posesión es el reposo, la pereza, el orgullo. Si Dios tuviese encerrada en su mano derecha toda la verdad y en su mano izquierda, la aspiración siempre en movimiento hacia la verdad misma con la condición de equivocarme siempre eternamente y me dijese: Escoge, asiría humildemente su mano izquierda y diría: -Dámela, Padre mío, pues la verdad pura sólo a ti te pertenece. ${ }^{21}$

Aquí se expresa el punto de partida luterano de la relación entre Dios y el hombre, esa oposición radical entre lo absoluto, lo infinito, lo que es omnisciente y omnipotente, por un lado, y el hombre, con su finitud y su permanente incertidumbre, por otro. La frase final muestra el único camino a transitar válidamente para el protestante: la acción, la obra, que apuesta por el esfuerzo del individuo en su afán de elevarse hacia lo divino, que opta por una fe a pesar de no tener la seguridad de conseguir lo que se propone. Sin lugar a dudas, esta parábola debió provocar el entusiasmo del joven Fichte, quien años más tarde construiría una filosofía en la que lo finito no resulta absorbido por lo absoluto y en la que el destino humano se resume en actuar, aunque nunca se alcance la perfección sino sólo el perfeccionamiento. ${ }^{22} \mathrm{Y}$, por supuesto, también debió concitar la admiración de Hegel, quien consideró que la razón, aunque absoluta, es histórica y se revela en un proceso dialéctico hasta alcanzar todas sus manifestaciones, parciales y relativas, a lo largo del desarrollo completo de la humanidad.

En consonancia con Lessing, pero no con Lutero, tanto Fichte como Hegel sostuvieron que la filosofía era superior a la religión. Para el primero, la filosofía incluía la religión junto con otras posibles perspectivas del mundo sintetizando a todas ellas. Algo parecido ocurría con Hegel, quien, a diferencia

${ }^{21}$ G. E. Lessing, "Eine Duplik", en Sämtliche Schriften, t. XVIII, p. 42.

${ }^{22}$ J. G. Fichte, "Algunas lecciones sobre el destino de sabio", en Fichtes Werke. Ed. de I. Fichte. Berlín, Walter de Gruyter, 1971, t. vI, p. 300. 
de Fichte, pensaba, además, que la filosofía se encontraba en un nivel superior a la religión por su capacidad de penetrar conceptualmente las verdades que ella sólo podía ofrecer mediante el sentimiento de la fe. ${ }^{23}$ Schelling, en cambio, dio lugar a una identidad entre filosofía y religión, cuya exteriorización más perfecta se encuentra en el arte, gracias al cual podría advenir una renovación espiritual a la humanidad mediante la creación de una comunidad estéticoreligiosa bien cohesionada. ${ }^{24}$

En un principio, podríamos interpretar muchas de estas ideas en continuidad con la Ilustración, por ejemplo, la de la antítesis entre sensibilidad e inteligencia, que aparece en Lessing en cuanto dicotomía entre verdades de hecho y de razón. En efecto, el Sturm und Drang, Schiller, el idealismo y el romanticismo hicieron una fuerte crítica a esta visión fragmentada del mundo, del ser humano y sus facultades, y consideraron que era fruto de la razón ilustrada, puramente teórica, mera inteligencia (Verstand), que se esfuerza por mantener la separación entre sujeto y objeto. Sin embargo, estas oposiciones están relacionadas también con la religiosidad protestante. Precisamente por eso, causaron tanta preocupación entre los pensadores alemanes e intentaron superarlas para finalmente reconocer que su origen estaba en el luteranismo. Los filósofos idealistas llevaron tales contradicciones a la máxima potencia y encontraron que todas ellas se condensaban y originaban en la oposición entre lo infinito y lo finito. ${ }^{25}$ Es más, Schelling afirmó que lo que caracteriza al idealismo es el intento de comprender ese tránsito entre opuestos explicando la realidad desde lo absoluto. Un tránsito, que probablemente nunca se habrían planteado si la religión protestante no hubiese presentado el encuentro con lo divino como una relación directa entre el individuo y Dios en la intimidad del corazón, eliminando la mediación del sacerdocio e incluso la de la comunidad, la de la iglesia. Como consecuencia de este rechazo, el protestantismo descartó también la confesión y el perdón de los pecados, generando culpa y una angustia, que en el estadio religioso, el del contacto inmediato con lo

${ }^{23}$ Cf. G. W. F. Hegel, Enciclopedia de las ciencias filosóficas. Trad. de R. Vals Plana. 2a. ed. Madrid, Alianza, 1999, \$\$ 64 y ss.

${ }^{24} \mathrm{Cf}$. F. W. J. Schelling, Sistema del idealismo trascendental, vi parte y Filosofía del arte. Trad. de V. López-Domínguez. Madrid, Tecnos, 1999, sección 1a.: "Construcción en conjunto y en general", $\$ \int 1$ y ss., pp. 25 y ss., y sección $2 a$.: "Construcción de la materia del arte", \$\$ 25 y ss., pp. 81 y ss.

25 Tanto para Schelling como para Hegel, el origen del filosofar se origina en la separación entre sujeto y objeto, que no es sino un reflejo de la escisión entre finito e infinito. Para Schelling, la escisión en su época se da esencialmente entre naturaleza y espíritu, mientras que para Hegel se da entre los hombres, en el ámbito socio-político. $C f$. F. W. J. Schelling, "Ideas para una filosofía de la naturaleza", en Schellings Werke, t. I, pp. 663 y ss., y G. W. F. Hegel, Diferencia entre los sistemas de filosofía de Fichte y Schelling. Trad. de M. C. Paredes. Madrid, Tecnos, 1990, pp. 12 y ss. 
divino, se exterioriza como temor y temblor - por utilizar la terminología de Kierkegaard. El requerimiento de un encuentro directo con lo divino pone en evidencia la imposibilidad de la conciencia de acercarse a lo infinito si no es a riesgo de su aniquilación. Y, dado que el idealismo reconoce que toda visión de la realidad es subjetiva, antropológica, aunque sea trascendental, el individuo no puede sino introyectar esta oposición dentro de sí para terminar convirtiéndose en una conciencia desgarrada. Así es como la escisión -tanto para Schelling como para Hegel- constituye el punto de partida del idealismo.

Del mismo modo, la necesidad idealista de salvaguardar la libertad humana en todos los campos y colocarla como cuestión central de la filosofía, en tanto que define al hombre y le confiere dignidad, se le puede interpretar en relación con el protestantismo y no tanto en referencia a la Revolución francesa, como muchas veces se suele hacer. Eso explicaría -como de hecho hizo Marcuse en su artículo sobre Lutero en el volumen editado por Horkheimer con el título de La autoridad y la familia $-{ }^{26}$ que en muchos de estos autores la libertad esté conectada con la necesidad. Como observa Marcuse, el punto de partida del protestantismo es la conciencia, que se encuentra totalmente libre para interpretar las escrituras y decidir en su vida, es el individuo que actúa según su libre albedrío. Pero, en la medida en que dicha conciencia se sitúa ante la omnipotencia divina, se convierte en esclava, queda aniquilada ante la voluntad de Dios e inoperante, si no es merced a la Gracia divina. Ya en Lutero, el libre arbitrio se convierte en servo arbitrio, es decir, que el protestantismo es desde el principio fatalista. Si además se admite que el reino divino es espiritual e interior, pero que, de algún modo, se trasunta en la obra, entonces se genera una vinculación entre la dignidad espiritual y la material, siendo esta última la expresión de la primera. Como observó bien Max Weber, esto hace que ciertas sectas, como la calvinista, consideren que la riqueza económica es fruto de la predeterminación providencialista. ${ }^{27}$ Sin embargo, no hay que llegar hasta Calvino para comprobar la creencia en el paralelismo entre el mundo anímico y el material sino que ya lo encontramos en Lutero, porque, del mismo modo que éste sancionó la exigencia de someterse al poder de Dios en el ámbito interior, de la conciencia y de la moral, promulgó la obligación de subordinarse a los príncipes en el ámbito político. El choque entre esos dos ámbitos opuestos, el de la libertad y el de la necesidad, se percibe en la

${ }^{26} C f$. H. Marcuse, "Estudio sobre la autoridad y la familia", en Para una crítica de la sociedad. Trad. de C. Lemoine. Caracas, Tiempo Nuevo, 1971, capítulo dedicado a Lutero y Calvino. La fuente de referencia para este tema es el De servo arbitrio de Lutero, obra escrita en respuesta a la concepción del libre albedrío de Erasmo de Rotterdam.

${ }^{27}$ Max Weber, La ética protestante y el espíritu del capitalismo. Introd. y ed. crítica de Francisco Gil Villegas. 2a. ed. México, FCE, 2011. 
filosofía de la época, hasta que se comprende que la mayor libertad consiste en la aceptación del destino como algo querido por la misma libertad. ${ }^{28}$ Así, por ejemplo, en Herder, especialmente en Otra filosofía de la historia ${ }^{29}$ vemos que se alterna la idea de una libertad radical del individuo para tomar decisiones junto con la creencia en un destino que impertérrito conduce nuestra vida. La misma contradicción la encontramos en Fichte, antes de haber leído la Crítica de la razón práctica.$^{30}$ A su vez, en Kant nos encontramos con una defensa irrestricta de la libertad de expresión a nivel público, pero un rechazo de la misma a nivel privado. ${ }^{31}$ En el fondo, el problema mayor es ese temor ante una posible rebelión frente a la autoridad política, la preocupación ante la desobediencia civil y el pánico a una revolución que comprometa la estabilidad de las estructuras jurídico-políticas devolviendo la sociedad al estado de naturaleza, concebido como lucha de todos contra todos. En definitiva, es el mismo miedo que lleva a Hegel a colocar el Estado como instancia última e insuperable de la eticidad y a decretar tanto la imposibilidad de su disolución como la creación de una sociedad cosmopolita. ${ }^{32}$

Finalmente, hay que decir que tanto Schelling como Hegel consideraron el cristianismo como inicio de una nueva etapa en la humanidad en la cual lo finito se desgajó de lo divino, que, en la religión griega se encontraba esparcido en el universo, habitando todos los seres de la naturaleza, incluido el hombre. Para Schelling, la ruptura se instaló entre el hombre y la naturaleza, mientras que para Hegel lo hizo entre los hombres afectando sus relaciones sociopolíticas. Lo importante en ambos casos es que los dos intentaron buscar una superación de ese estado de escisión y, en el ámbito de la religión, ambos encontraron un modelo en el catolicismo contrarreformista, ${ }^{33}$ porque

${ }^{28}$ Ésta es la concepción más elevada de la libertad que, para Schelling, emana de la tragedia. Véase la carta 10 de sus Cartas sobre dogmatismo y criticismo o la Filosofía del arte, pp. 439-456, así como mi artículo "Sobre la idea de tragedia como reconciliación en Schelling: la libertad y el mal”, en Revista de Humanidades. Santiago de Chile, UAB, 2015, núm. 31, pp. 58-76. En el caso de Fichte y Hegel, la libertad se presenta como necesidad interna de la razón.

${ }^{29}$ J. G. Herder, "Otra filosofia de la historia", en Obra selecta, p. 320.

${ }^{30} \mathrm{Cf}$. Aforismos sobre religión y deísmo, obra de Fichte, inconclusa e inédita en vida, escrita en julio de 1790. Sobre el determinismo del joven Fichte, véase mi libro: Fichte: acción y libertad, pp. 35-40.

${ }^{31}$ I. Kant, "Respuesta a la pregunta: ¿Qué es la ilustración?", en Filosofía de la historia. Trad. de E. Tabernig. Buenos Aires, Nova, 1958.

${ }^{32}$ G. W. F. Hegel, Enciclopedia de las ciencias filosóficas, $\$ \int 535-552$, pp. 551 y ss.

${ }^{33}$ La lucha de los románticos e idealistas contra la escisión, que separa lo finito y lo infinito reproduciendo la ausencia de mediación entre Dios y el hombre propia del protestantismo, hizo que algunos de ellos se inclinaran hacia el catolicismo, de forma explícita, como en el caso de la conversión de Fr. Schlegel, o sólo teóricamente, como ocurre con Novalis, por ejemplo, en Cristiandad o Europa y los Himnos a la noche. 
introduce figuras mediadoras entre Dios y el hombre, admite la confesión y el perdón de los pecados, coloca al sacerdote como representante de la comunidad y, con su parafernalia, convierte el servicio religioso en una auténtica obra de arte.

En cuanto a Schelling, su reivindicación de Calderón como el trágico que anuncia un nuevo periodo en la humanidad donde se sintetizará lo antiguo y lo moderno, y el reconocimiento del servicio religioso como único acto público de la modernidad, esto es, como una obra de arte, son formas de avalar el rito, la función mediadora del sacerdote y el concepto de comunidad propio de la Iglesia católica (véase Filosofía del arte, pp. 726-730 y pp. 771-773). En el caso de Hegel, la reparación de la herida de la autoconciencia se da a través de la Iglesia católica, que representa una prefiguración de la razón (véase La fenomenología del espíritu: "La autoconciencia; 3. La conciencia desventurada. Subjetivismo piadoso; g) Aglutinación de lo real y la autoconciencia", pp. 297-301). En el ámbito del espíritu, la reconciliación se da a través de la confesión y el perdón de los pecados (ibid., "El espíritu cierto de sí mismo. La moralidad; 3. El mal y su perdón; g) Perdón y reconciliación”, pp. 771-773). 